\title{
Fascinating reactivity in gold catalysis: Synthesis of oxetenes through rare 4-exo-dig allene cyclization and infrequent $\beta$-hydride elimination
}

\author{
Benito Alcaide, ${ }^{a}$ Pedro Almendros, ${ }^{* b}$ Teresa Martínez del Campo, ${ }^{a}$ and Israel Fernández ${ }^{c}$ \\ Received (in $X X X, X X X) X$ th $X X X X X X X X X 20 X X$, Accepted $X$ th $X X X X X X X X X 20 X X$ \\ DOI: 10.1039/b000000x
}

A novel reactivity in gold catalysis, namely the unusual preference for the 4-exo-dig cyclization in allene chemistry as well as the rare $\beta$-hydride elimination reaction, was uncovered starting from readily available allenols.

10 The transition-metal-catalyzed cyclization of allene derivatives bearing a nucleophilic functionality has led to many synthetically useful transformations. ${ }^{1,2}$ However, regioselectivity problems are significant (endo-trig versus endo-dig versus exo-dig versus exotrig cyclization). The metal catalyst can coordinate to either 15 allenic double bond, depending the regioselectivity of the attack both on the structure of the substrate and the nature of the catalyst. Four different products can be obtained, but the formation of five- or six membered rings is favored. The last decade has witnessed dramatic growth in the number of reactions 20 catalyzed by gold complexes because of their powerful soft Lewis acidic nature. ${ }^{3,45}$ Thus, it is not surprising that gold salts are ranked among the best catalysts for the selective activation of the allene moiety. ${ }^{6}$ An important, yet unexamined, subject in the field of Au-catalyzed cyclizations is how to control the reaction 25 selectivity for the substrates carrying different allene substitution patterns. Importantly, it should be remarked that reports on the synthesis of strained rings such as four-membered heterocycles are lacked in the gold chemistry of allenes. Besides, taking into consideration the chemical and medicinal interest of oxetanes, ${ }^{7}$ 30 the direct synthesis of oxetane derivatives from allenols emerged as an attractive transformation to develop.

Despite the efficiency of the recently discovered goldcatalyzed cycloisomerization reaction of $\alpha$-hydroxyallenes to yield dihydrofurans, ${ }^{6,8}$ the introduction of a wide range of 35 substituents on the allene group needs to be explored in order to expand its application in the synthesis of useful chemicals. Traditionally, metal-catalyzed cyclizations on $\alpha$-allenols favor a 5-endo-trig pathway. ${ }^{6,8}$ Owing to our interest in metal-catalyzed processes employing alkynes and allenes, ${ }^{9}$ we were attracted to 40 the possibility that a non-five-membered heterocycle could be accessed by variation of the allene substitution. We hypothesized that the product selectivity could be impacted by modulating the relative stability of the $\eta^{2}$ complexes generated by $\pi$-coordination of the metal to the $\mathrm{C}=\mathrm{C}$ bonds during the course of the reaction.

45 Starting allenols were prepared from salicylaldehyde derivatives via regiocontrolled indium-mediated Barbier-type carbonyl-allenylation reaction in aqueous media adopting our methodology. ${ }^{10}$ In our study on the possibility of selectivity reversal in $\mathrm{Au}$ catalysis, methyl-substituted allenol 1a and 50 phenyl-substituted allenol 1c were used as the model compounds and $\mathrm{AuCl}_{3}$ as the catalyst to describe the experiments. The reaction in dichloromethane proceeded smoothly for both substrates. Allenol 1a afforded the expected cycloisomerization adduct, dihydrofuran 2a. However, as a first try, we were happy 55 to notice that the reaction of phenyl-derivative 1c afforded oxetene 3c as major component (42\% isolated yield), even dihydrofuran 2c was also isolated as minor component (17\%). Thus, when the reaction was performed using $\mathbf{1 c}$ instead of 1a, a switch of the regioselectivity was observed. Encouraged by this 60 preliminary result and with the optimal reaction conditions established, the scope of this novel oxycyclization reaction was then studied. To our great delight, the reaction of phenylderivatives $\mathbf{1 d}$ and $\mathbf{1 e}$ afforded the oxetenes $\mathbf{3 d}$ and $\mathbf{3 e}$ as the sole products in good yields (Scheme 1). This intriguing 65 transformation can be explained invoking a uncommon allene 4exo-dig cyclization as well as an infrequent $\beta$-hydride elimination reaction in gold catalysis $(\mathrm{C}-\mathrm{Au}$ bonds prefers protodeauration over $\beta$-hydride elimination; indeed, gold-hydrides are rare species and difficult to access). ${ }^{11,12,13}$

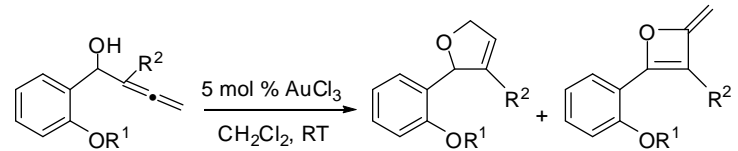

1a $R^{1}=$ prop-2-enyl, $R^{2}=$ Me $\quad$ 2a (71\%)

1b $\mathrm{R}^{1}=2$-methylallyl, $\mathrm{R}^{2}=\mathrm{Me} \quad \mathbf{2 b}(51 \%)$

1c $R^{1}=$ prop-2-enyl, $R^{2}=P h \quad$ 2c $(17 \%)$

$1 d \mathrm{R}^{1}=2$-methylallyl, $\mathrm{R}^{2}=\mathrm{Ph}$

1e $\mathrm{R}^{1}=2$-bromoallyl, $\mathrm{R}^{2}=\mathrm{Ph}$

1f $R^{1}=$ methyl, $R^{2}=P h$

$3 c(42 \%)$

3d $(62 \%)$

3e $(85 \%)$

2f $(31 \%) \quad$ 3f $(23 \%)$

$\mathbf{1} \mathbf{g ~ R}^{1}=$ prop-2-ynyl, $\mathrm{R}^{2}=\mathrm{Ph} \quad \mathbf{2 g}(22 \%) \quad \mathbf{3 g}(30 \%)$

1h $\mathrm{R}^{1}=(E)$-(4-chlorobut-2-enyl), $\mathrm{R}^{2}=\mathrm{Ph} \quad 2 \mathrm{~h}(22 \%) \quad 3 \mathbf{h}(33 \%)$

1i $\mathrm{R}^{1}=2$-methylallyl, $\mathrm{R}^{2}=4-\mathrm{MeOC}_{6} \mathrm{H}_{4}$

1k R ${ }^{1}=2$-methylallyl, $\mathrm{R}^{2}=4-\mathrm{BrC}_{6} \mathrm{H}_{4} \quad \mathbf{2 k}(44 \%) \quad 3 \mathbf{3 k}(25 \%)$

Scheme 1 Divergent oxycyclization reactions of $\alpha$-allenols 1 under gold catalysis.

The incorporation of different substituents at the salicylaldehyde-derived allenol was tested next. As revealed in 75 Scheme 1, various aryl-substituted allenols $\mathbf{1 f - i}$ were suitable for such heterocyclization reaction. For example, the $p$ methoxyphenyl substituent at the allene side was tolerated. Similarly, the ether chain bearing methoxy, $(E)-(4-c h l o r o b u t-2-$ enyl)oxy, or propargyloxy moieties also afforded the desired 80 oxetenes, but not as the unique product. Starting from allenols 1c, and $\mathbf{1 f}-\mathbf{h}$, and performing the reaction at room temperature, a mixture of two different products arises from competitive 4-exo- 
dig versus 5-endo-trig cyclizations (Scheme 1). Interestingly, allenols 1c, and $\mathbf{1 f}-\mathbf{h}$ under $\mathrm{AuCl}_{3}$ catalysis in dichloromethane at reflux temperature gave as the sole or major product the oxetene component (Scheme S1). Thus, it is possible to suppress or 5 minimize the formation of the dihydrofuran ring (cycloisomerization adduct) by performing the reaction at higher temperature, yielding the oxetene (oxycyclization/ dehydrogenation adduct) as the exclusive or major product. A general trend can be deduced on the basis of these results: the 10 four-membered oxetene is the thermodynamic control product while the dihydrofuran is the kinetic control product.

A possible pathway for the gold-catalyzed achievement of dihydrofurans 2 may initially involve the formation of a complex 4 through coordination of the gold trichloride to the distal allenic 15 double bond of $\alpha$-allenols 1 . Next, regioselective 5-endo-trig oxyauration forms zwitterionic intermediates 5, which after loss of $\mathrm{HCl}$ generate neutral species 6. Protonolysis of the carbongold bond of $\mathbf{6}$ liberates adducts $\mathbf{2}$ with concurrent regeneration of the Au(III) catalytic species (Scheme 2, left catalytic cycle).

20 A mechanistic rationale for the gold-catalyzed conversion of aryl-substituted allenols $\mathbf{1}$ into oxetenes $\mathbf{3}$ is more intricate. It is worth noting that the cyclization affords cycloadducts $\mathbf{3}$ from a 4 exo-dig cyclization/dehydrogenation process instead of that from the usually preferred 5-endo-trig cycloisomerization reaction. The 25 pathway proposed in Scheme 2 (right catalytic cycle) looks valid for the formation of products type 3 . It could be presumed that the initially formed gold complex 4, through coordination of the $\mathrm{AuCl}_{3}$ to the distal allenic double bond, undergoes an intramolecular attack (rare 4-exo-dig versus normal 5-endo-trig 30 oxyauration) by the hydroxy group, giving rise to the oxetene intermediate 7. Loss of $\mathrm{HCl}$ in intermediate $\mathbf{7}$ generates neutral species 8, which after 1,3-gold migration ${ }^{11}$ leads to the formation of oxetane species 9. Uncommon $\beta$-hydride elimination rather than protonolysis of the carbon-gold bond, ${ }^{12,13,14}$ linked to a 35 reaction of $\mathrm{HCl}$ with the gold hydride would then liberate the oxacycle type $\mathbf{3}$ with concomitant regeneration of the catalytic $\mathrm{Au}(\mathrm{III})$ salt. In the conversion of intermediate $\mathbf{9}$ into alkylideneoxetenes 3 , a possible alternative step to the beta-hydride elimination should involve a direct transfer of the hydride to the 40 proton of $\mathrm{HCl}$, thus re-forming $\mathrm{AuCl}_{3}$ and $\mathrm{H}_{2}$. ${ }^{15}$

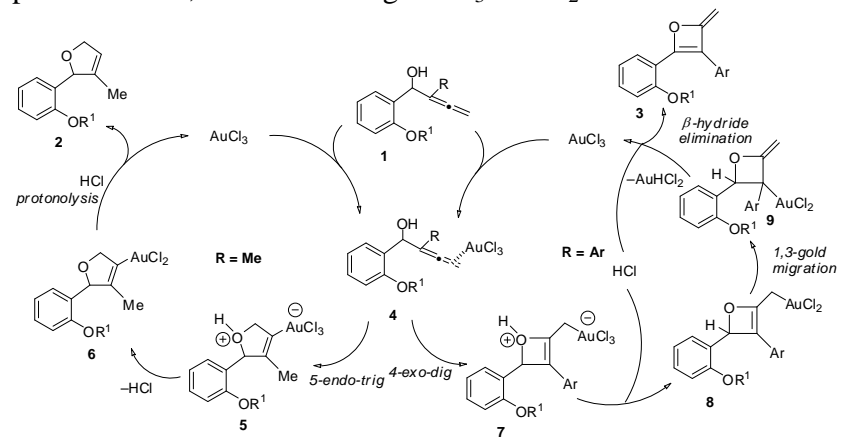

Scheme 2 Mechanistic explanation for the gold-catalyzed oxycyclization of methyl- and aryl substituted $\alpha$-allenols $\mathbf{1}$.

A coordination to the internal $\mathrm{C}-\mathrm{C}$ double bond would 45 similarly lead to intermediate $\mathbf{9}$ (see Scheme S4).

To gain more insight into the reaction mechanisms of the above gold-catalyzed oxycyclization reactions, a computational (DFT) study was carried out. The corresponding computed reaction profiles (PCM-B3LYP/def2-SVP level) ${ }^{16}$ of methyl- and 50 phenyl-substituted allenols $\mathbf{1 j}$ and $\mathbf{1 f}$ are shown in Scheme 3, which gathers the respective free energies in $\mathrm{CH}_{2} \mathrm{Cl}_{2}$ solution.

As initially envisaged, two different coordination modes of the metal fragment to the allenic double bond, i.e. distal vs proximal, are possible. Our calculations indicate that although the proximal 55 approach is slightly more exergonic, the subsequent 4-endo-dig oxycyclization reaction (from complex $\mathbf{1 0}$ via transition state TS4) is clearly kinetically disfavored respect to the corresponding 5-endo-trig or 4-exo-dig processes in view of the much higher activation barrier of the former transformation. Thus, the 60 oxycyclization reactions start from the common intermediate complex 4, formed through coordination of $\mathrm{AuCl}_{3}$ to the distal allenic double bond of $\mathbf{1 j}$,f.

As readily seen in Scheme 3, the 5-endo-trig reaction forms the zwitterionic complex 5 through an exergonic process $\left(\Delta \mathrm{G}_{\mathrm{R}, 298}=-\right.$ 659.5 and $-9.9 \mathrm{kcal} / \mathrm{mol}$ for $\mathrm{R}=\mathrm{Me}$ and $\mathrm{R}=\mathrm{Ph}$, respectively) via TS1 with a very low activation barrier $\left(\Delta \mathrm{G}^{\neq}{ }_{298}=+3.3\right.$ and +4.1 $\mathrm{kcal} / \mathrm{mol}$ ). The sequential loss of $\mathrm{HCl}$, which forms neutral species 6, and protonolysis of the $\mathrm{C}-\mathrm{Au}$ bond via TS3 produces the final dihydrofuran 2 regenerating the catalyst. Interestingly, 70 the barrier energy of this step is clearly more favorable when $\mathrm{R}=$ Me than when $\mathrm{R}=\mathrm{Ph}\left(\Delta \Delta \mathrm{G}^{\neq}{ }_{298}=6.0 \mathrm{kcal} / \mathrm{mol}\right)$, which is in nice agreement with the preferential formation of dihydrofurans 2 at expenses of oxetenes $\mathbf{3}$ for methyl-substituted allenols 1a,b (see Scheme 1).

75 The 4-exo-dig process, which transforms complex 4 into 7 via TS2, also occurs with a low activation barrier $\left(\Delta \mathrm{G}^{\neq} 298=+7.6\right.$ and $+7.8 \mathrm{kcal} / \mathrm{mol}$ for $\mathrm{R}=\mathrm{Me}$ and $\mathrm{R}=\mathrm{Ph}$, respectively) in an exergonic transformation as well. Despite that, the barrier energies are higher than those computed for the 5-endo-trig 80 process, thus indicating that the latter reaction is kinetically favored. Nevertheless, the low barriers of both processes should be translated into a mixture of reaction products, as experimentally found (see Scheme 1). Strikingly, the computed reaction energy difference between both nucleophilic additions ${ }_{85}$ indicates that whereas the 5-endo-trig reaction is thermodynamically favored when $\mathrm{R}=\mathrm{Me}\left(\Delta \Delta \mathrm{G}_{\mathrm{R}, 298}=+5.1\right.$ $\mathrm{kcal} / \mathrm{mol})$, the 4-exo-dig reaction is favored when $\mathrm{R}=\mathrm{Ph}$ $\left(\Delta \Delta \mathrm{G}_{\mathrm{R}, 298}=-2.2 \mathrm{kcal} / \mathrm{mol}\right)$. This justifies the formation of oxetenes $\mathbf{3}$ as the major reaction product when the reaction is 90 conducted under reflux conditions (see Scheme S1). Loss of $\mathrm{HCl}$ in intermediate $\mathbf{7}$ generates neutral species $\mathbf{8}$. This step is much easier than the corresponding loss of $\mathbf{H C l}$ which transforms $\mathbf{5}$ into 6 due to close proximity of the hydrogen and chlorine atoms in complex 7 (computed $\mathrm{H} \cdots \mathrm{Cl}$ distance of 1.822 and $1.830 \AA$ for $\mathrm{R}$ ${ }_{95}=\mathrm{Me}$ and $\mathrm{R}=\mathrm{Ph}$, respectively). Complex $\mathbf{8}$ isomerizes into 8'-bis after re-coordination of the metal fragment and is converted into complex 9 through TS5 (a saddle point associated with the 1,3migration of the metal moiety). ${ }^{11}$ Finally, a $\beta$-hydride elimination reaction occurs (via TS6) ${ }^{16}$ to produce the final oxetene 3 and $100 \mathrm{AuHCl}_{2}$ (which would regenerate the initial catalyst upon reaction with $\mathrm{HCl}$ ). From the data in Scheme 3, it becomes obvious that this step constitutes the bottle-neck of the process when $\mathrm{R}=\mathrm{Ph}\left(\Delta \mathrm{G}^{\neq}{ }_{298}=+21.1 \mathrm{kcal} / \mathrm{mol}\right)$ but is kinetically favored over the corresponding $\mathrm{Au}-\mathrm{C}$ protonolysis involving TS3 and 105 leading to dihydrofuran $\mathbf{2 f}$.

Therefore, it can be concluded that whereas the 5-endo-trig $\rightarrow$ 
loss of $\mathrm{HCl} \rightarrow$ protonolysis sequence (which produces dihydrofurans 2) is followed for methyl-substituted allenols, the 4-exo-dig $\rightarrow$ loss of $\mathrm{HCl} \rightarrow$ 1,3-Au-migration $\rightarrow \beta$-elimination pathway (which leads to oxetenes 3 ) is preferred for phenyl-
5 substituted allenols. Both processes share the same common intermediate $\mathbf{4}$, formed through distal coordination of the allenic double bond, and are strongly favored over the corresponding 4endo-dig pathway involving the proximal coordination.

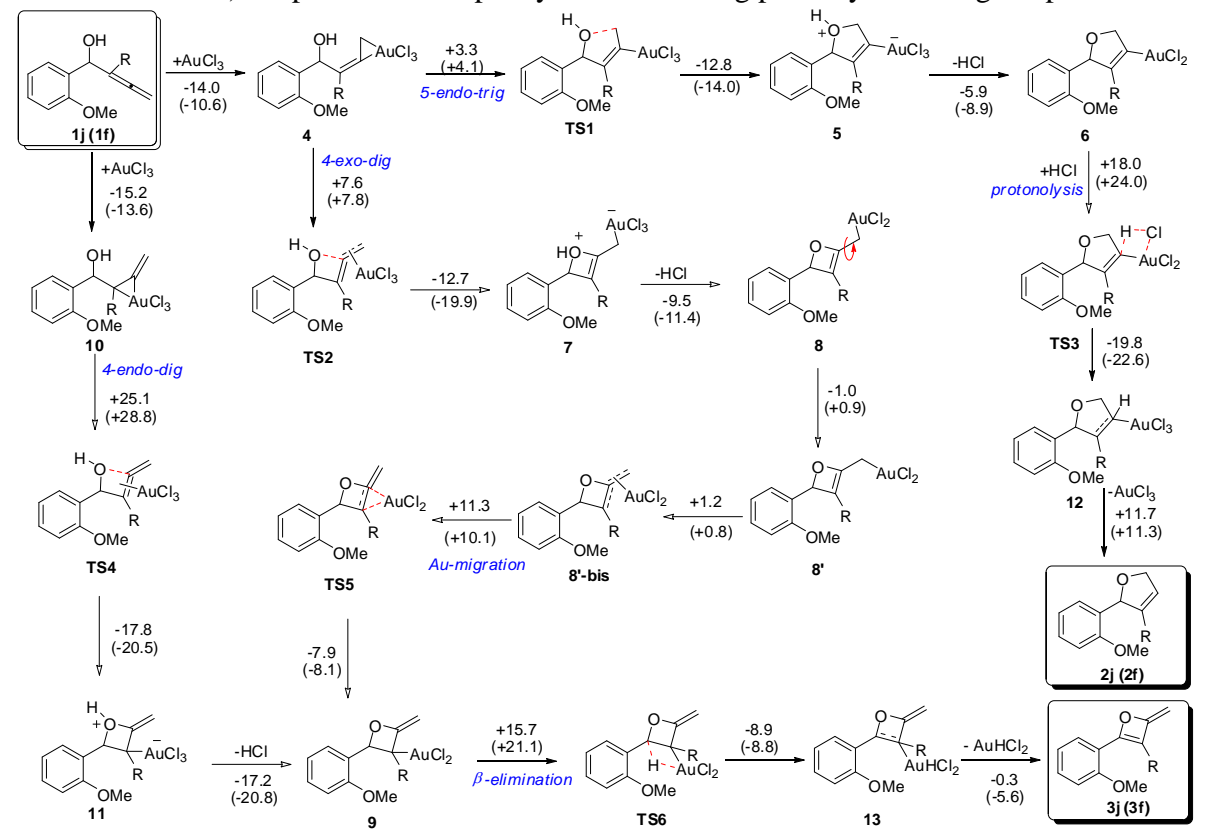

10 Scheme 3 Computed reaction profile for the gold-catalyzed oxycyclization reactions of allenols $\mathbf{1} \mathbf{j}(\mathrm{R}=\mathrm{Me}$, plain values) and $\mathbf{1 f}(\mathrm{R}=\mathrm{Ph}$, values in parenthesis). Free energies ( $\Delta \mathrm{G}_{298}$, in $\mathrm{kcal} / \mathrm{mol}$ ) have been computed at the PCM $\left(\mathrm{CH}_{2} \mathrm{Cl}_{2}\right)$-B3LYP/def2-SVP level.

Acknowledgment. Support for this work by the MICINN [CTQ2009-09318, CTQ2010-20714-C02-01, and ConsoliderIngenio 2010 (CSD2007-00006)], CAM (Projects S2009/PPQ151752 and S2009/PPQ-1634), UCM-Santander (Grant GR35/10-

A) are gratefully acknowledged. I.F. is a Ramón y Cajal fellow.

\section{Notes and references}

${ }^{a}$ Grupo de Lactamas y Heterociclos Bioactivos, Departamento de Química Orgánica, Unidad Asociada al CSIC, Facultad de Química, 20 Universidad Complutense de Madrid, 28040-Madrid, Spain. Fax: +34 91-3944103; E-mail: alcaideb@quim.ucm.es

${ }^{b}$ Instituto de Química Orgánica General, IQOG, CSIC, Juan de la Cierva 3, 28006-Madrid, Spain. Fax: +34 91-5644853; E-mail: Palmendros@iqog.csic.es

$25{ }^{c}$ Departamento de Química Orgánica, Facultad de Química, Universidad Complutense de Madrid, 28040-Madrid, Spain

$\dagger$ Electronic Supplementary Information (ESI) available: Experimental procedures, characterization data of new compounds, and copies of NMR spectra. See DOI: 10.1039/b000000x/

зо 1 For selected reviews, see: (a) Cumulenes and Allenes, Science of Synthesis, Houben-Weyl Method of Molecular Transformation, vol. 44, ed. N. Krause, George Thieme, Sttutgart, 2007; (b) S. Ma, Chem. Rev., 2005, 105, 2829; (c) Modern Allene Chemistry, eds. N. Krause and A. S. K. Hashmi, Wiley-VCH, Weinheim, 2004.

352 (a) B. Alcaide, P. Almendros and C. Aragoncillo, Chem. Soc. Rev., 2010, 39, 783; (b) M. Brasholz, H.-U. Reissig and R. Zimmer, Acc. Chem. Res., 2009, 42, 45; (c) B. Alcaide and P. Almendros, Eur. J. Org. Chem., 2004, 3377; (d) A. S. K. Hashmi, Angew. Chem. Int. Ed., 2000, 39, 3590 .

403 For selected examples, see: (a) A. S. K. Hashmi, Angew. Chem. Int. Ed., 2010, 49, 5232; (b) A. S. K. Hashmi, Chem. Rev., 2007, 107, 3180.

4 (a) Chem. Rev., 2008, 108, issue 8, eds. B. Lipshutz and Y. Yamamoto; (b) Chem. Soc. Rev., 2008, 37, issue 9, eds. G. J.
5 (a) A. Corma, A. Leyva-Pérez, M. J. Sabater, Chem. Rev., 2011, 111, 1657; (b) J. Muzart, Tetrahedron, 2008, 6, 5815.

6 (a) N. Krause and C. Winter, Chem. Rev., 2011, 111, 1994; (b) N. Bongers and N. Krause, Angew. Chem. Int. Ed., 2008, 47, 2178.

507 J. A. Burkhard, G. Wuitschik, M. Rogers-Evans, K. Müller and E. M. Carreira, Angew. Chem. Int. Ed., 2010, 49, 9052.

8 (a) A. Hoffmann-Röder and N. Krause, Org. Lett., 2001, 3, 2537; (b) A. S. K. Hashmi, M. C. Blanco, D. Fischer, J. W. Bats, Eur. J. Org. Chem., 2006, 1387; (c) M. Asikainen and N. Krause, Adv. Synth. 55 Catal., 2009, 351, 2305; (d) D. Eom, D. Kang and P. H. Lee, J. Org. Chem., 2010, 75, 7447.

9 See, for instance: (a) B. Alcaide, P. Almendros and R. Carrascosa, Chem. Eur. J., 2011, 17, 4968; (b) B. Alcaide, P. Almendros and M. T. Quirós, Adv. Synth. Catal., 2011, 353, 585; (c) B. Alcaide, P. Almendros and T. Martínez del Campo, Angew. Chem. Int. Ed., 2007, 46, 6684.

10 B. Alcaide, P. Almendros and T. Martínez del Campo, Angew. Chem. Int. Ed., 2006, 45, 4501.

11 A. S. K. Hashmi, A. M. Schuster, S. Litters, F. Rominger, M. 65 Pernpointner, Chem. Eur. J., 2011, 17, 5661.

12 A. S. K. Hashmi and G. J. Hutchings, Angew. Chem. Int. Ed., 2006, 45, 7896.

13 B. Alcaide, P. Almendros, T. Martínez del Campo, E. Soriano and J. L. Marco-Contelles, Chem. Eur. J., 2009, 15, 9127.

7014 H. Ito, T. Saito, T. Miyahara, C. Zhong and M. Sawamura, Organometallics, 2009, 28, 4829.

15 We thank a reviewer for bringing this pathway to our attention. Despite this mechanistic scenario cannot be completely ruled out, it seems less unlikely taking into account the computed high activation

75 barrier of this particular step (see Scheme S2). Besides, the preparation of oxetene 3d from allenol 1d was also accomplished using $\mathrm{Pt}(\mathrm{II})$ catalysis (see Scheme S3), probably involving the formation of well known platinahydride species. It can be suggested that the hydride transfer to $\mathrm{HCl}$ occurs from $\mathrm{AuHCl}_{2}$ to form $\mathrm{H}_{2}$ regenerating $\mathrm{AuCl}_{3}$.

16 See Computational Details in the Supplementary Information. 


\section{Graphical Abstract}

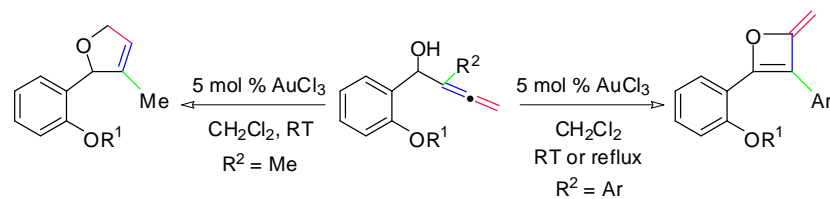

A novel reactivity in gold catalysis, namely the unusual preference for the 4-exo-dig cyclization in allene chemistry as well as the rare $\beta$-hydride elimination reaction, was uncovered starting from readily available allenols and using a simple gold catalyst.

Autores: Alcaide, B.; Almendros, P.; Martínez del Campo, T.; Fernández, I.

Título: Fascinating Reactivity in Gold Catalysis: Synthesis of Oxetenes through Rare 4-exo-dig Allene Cyclization and Infrequenț $\beta$-Hydride Elimination

Revista: Chem. Commun. 2011, 47, 9054-9056 